\title{
Review of Scrap Reduction Methodologies
}

\author{
Arpita R. Shukla, M.Tech CAD/CAM, G.H. Raisoni College of Engineering, Nagpur, India \\ shukla_arpita.ghrcemtechcad@ raisoni.net
}

\begin{abstract}
Scrap is the recyclable material left over after the manufacturing and consumption of the raw materials and goods such as vehicle parts, raw materials during manufacturing, etc. In contrast to waste, scrap has financial value. Excess generation of scrap affects the productivity of the industry. This paper discusses the requirements and different techniques or methodologies to reduce Scrap generation in the fabrication industries.
\end{abstract}

\section{Keywords - Manufacturing, Scrap, Productivity, Raw material, Scrap reduction, Manufacturing}

\section{INTRODUCTION}

Scrap is the recyclable material left over after the consumption of the raw materials during manufacturing. Manufacturing scrap is also seen as unavoidable result, something that occurs as unavoidable consequences of manufacturing cycle. Although, some of the manufacturing waste from scrap production is unpreventable, scrap production can actively oppose and affects the profit margins and bottom lines of the business. In the perfect case scenario, the scrapped materials and parts can be finished again and used for reuse and rework. However, in the worst case scenario, the part had to be dragged out entirely to be reprocessed into manufactured goods. It can extremely inefficient of both money and precious production time. The removal of scrap in the production sector is also an essential aspect of the lean and competitive manufacturing process.

\section{LiterATURE REVIEW}

Some research work has been done on this topic-

1] Kumar et al.(2009) highlighted the scrap reduction by using Total Quality Management Tools. Author used Cause and effect diagram and Validation Theory for Analysis. Also the Pareto Analysis is used to present the collected data in the form graph.

2] Ferretti et al. (2013) suggested the actions implemented for manufacturing of products with zero defects. Authors categorize the important actions in Indirect and Direct actions involved in manufacturing process. Also the Importance of Preventive maintenance of machines, Visual inspection of raw materials, Dimensional control of product and Optimization of production process parameters are discussed.

3] Huda et al. (2018) used Lean Six Sigma Methodology to increase the productivity. For analysis, the cause and effect diagram and 5 why's method is used to identify the main root cause.

4] Shokri et al.(2019) investigated the importance of Lean Six Sigma Method for scrap rate reduction in an automotive sector. The cause and effect diagram and
DMAIC Methodologies are used in order to reduce the variations. Author used Pareto chart to present the collected data in the graphical form.

\section{WORK METHOdOLOGY}

In the above Literature study, different methodologies are discussed to reduce scrap. The analysis is carried out by using Cause and effect diagram and 5 why's methods. Authors used Pareto charts and Control charts for showing the collected data and information in graphical form. DMAIC and Lean Six Sigma Methodologies are used to reduce variations and increase productivity.

1] Cause and Effect diagram - The "Cause and effect diagram" is created by Dr. Kaoru Ishikawa. This Technique is also known as Fishbone Diagram and Ishikawa Diagram. This tool is considered as one of the seven quality tools and works as an analysis tool. This technique is used to identify many possible causes for the main problem or effect. It is used to structure or define a brainstorming session.

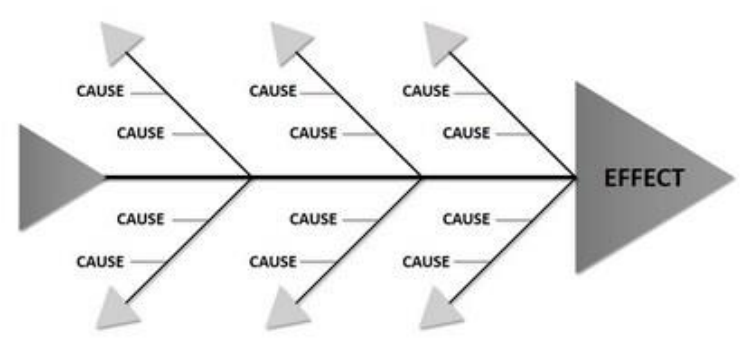

Figure 1 - Cause and Effect diagram

2] 5 Why's Technique - This technique is an Iterative Interrogative Method which is used to explore the relationships of cause and effect diagrams for a particular problem. This method is used to identify the root cause of the problem by asking a different sequence of a question "Why?" 


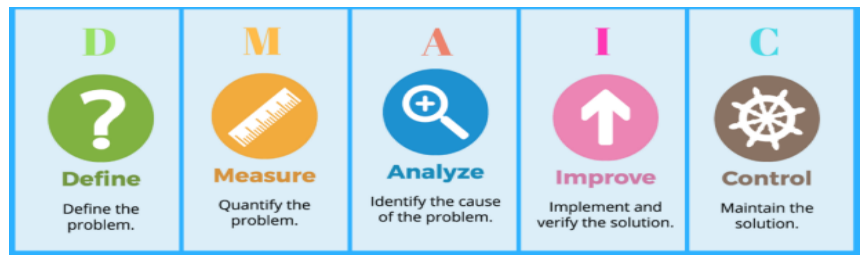

Figure 2 - 5 Why's Technique

3] Pareto Analysis - Pareto analysis is a statistical technique of decision making which is used to highlight the important set of barriers or factors. It contains both bars as well as line graphs, where individual values of study is represented by bars in descending order and line represents the total cumulative.

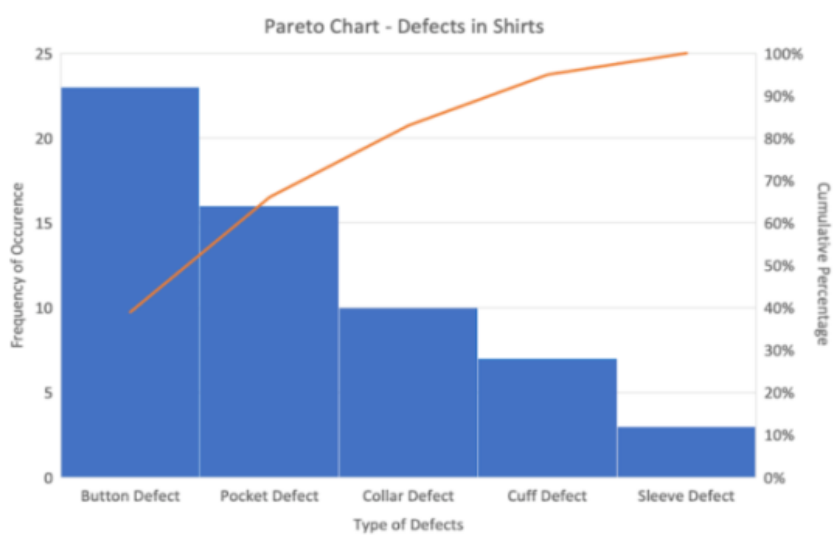

Figure 3 - Pareto Analysis

4] DMAIC Methodology - DMAIC Methodology is a strategy used to improve the Industrial process. The acronym DMAIC represents the five different phases (Define, Measure, Analyze, Improve and Control) to create an improvisation in the processes. DMAIC is a part of Lean Six Sigma.

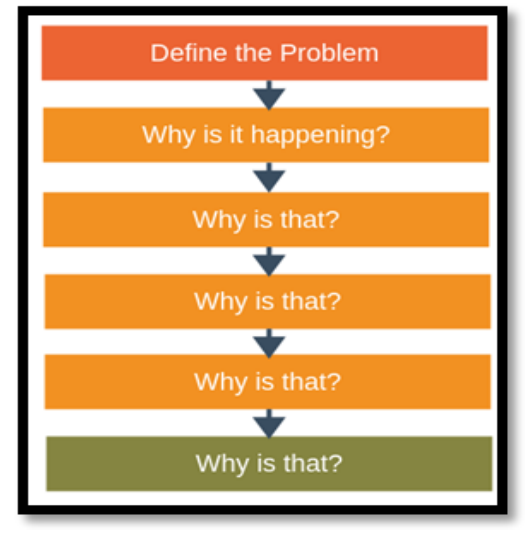

Figure 4 - DMAIC Methodology

\section{Conclusions}

Scrap Generation decreases the productivity of the Industries. There are various techniques and methodologies which can be used to reduce the scrap generation. This Paper suggests different techniques to identify the root cause of scrap generation like - Cause and Effect Diagrams,
5 Why's Technique, Pareto Analysis and DMAIC Methodology.

One of the simplest ways of reducing scrap is by optimizing the manufacturing process of the industry. By using Automated machines or tools to perform manufacturing process will reduce unwanted material waste. CNC machines are very effective for this purpose, but it is important to select the right machine for a particular task. It is important to know the value of proper documentation when the manufacturing industry is busy building. Proper documentation gives the information that how many materials are used and how much is left over. Proper Planning and documentation of ordered products and materials used can also minimize waste in manufacturing.

\section{REFERENCES}

[1] S. Ferretti, D. Caputo, et al, "Monitoring Systems for Zero Defect Manufacturing", Procedia CIRP, vol. 12, pp. 258263, 2013. Available: 10.1016/j.procir.2013.09.045.

[2] S. Kumar, D. Mantha and D. Kumar, "Scrap Reduction By Using Total Quality Management Tools", International Journal of Industrial Engineering, no. 1943-670, pp. 364369.

[3] Z. Mpanza (2016) 'Identifying the root causes contributing to defects in order to minimize scrap', International Conference on Industrial Engineering and Operations Management, pp. 1139-1146

[4] D. Raju (2016). Optimization of Process Parameters of Plasma Arc Cutting Using Taguchi's Robust Design Methodology. IOSR Journal of Mechanical and Civil Engineering, 16(053), 124-128. doi: 10.9790/16841605303124128.

[5] N. Abhimanyu and B. Satyanarayana (2016) 'Optimization of CNC Laser Cutting Process Parameters ', International Advanced Research Journal in Science, Engineering and Technology, Vol. 3(Issue 5).

[6] L. Huda, "The effect of material productivity on scrap reduction on aluminum reduction pot process", IOP Conference Series: Materials Science and Engineering, vol. 309, p. 012117, 2018. Available: 10.1088/1757$899 \mathrm{x} / 309 / 1 / 012117$

[7] A. Shokri, "Reducing the Scrap Rate in Manufacturing SMEs Through Lean Six Sigma Methodology: An Action Research", IEEE Engineering Management Review, vol. 47, no. 3, pp. 104-117, 2019. Available: 10.1109/emr.2019.2931184.

[8] P. Shinde, S. Shinde, A. Kalunge and S. Rokade, "Scrap Reduction Techniques", International Research Journal of Engineering and Technology (IRJET), vol. 06, no. 022019, 2019. 